PREPARED FOR THE U.S. DEPARTMENT OF ENERGY, UNDER CONTRACT DE-AC02-76CH03073

PPPL-3615

PPPL-3615

UC-70

Observation of Compressional Alfvén Modes during Neutral Beam

Heating on the National Spherical Torus Experiment

by

E.D. Fredrickson, N. Gorelenkov, C.Z. Cheng, R. Bell, D. Darrow,

D. Johnson, S. Kaye, B. LeBlanc, J. Menard, S. Kubota, and W. Peebles

October 2001

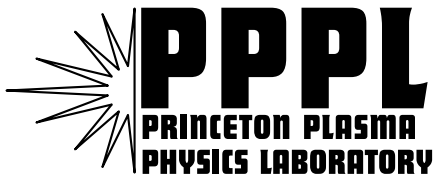

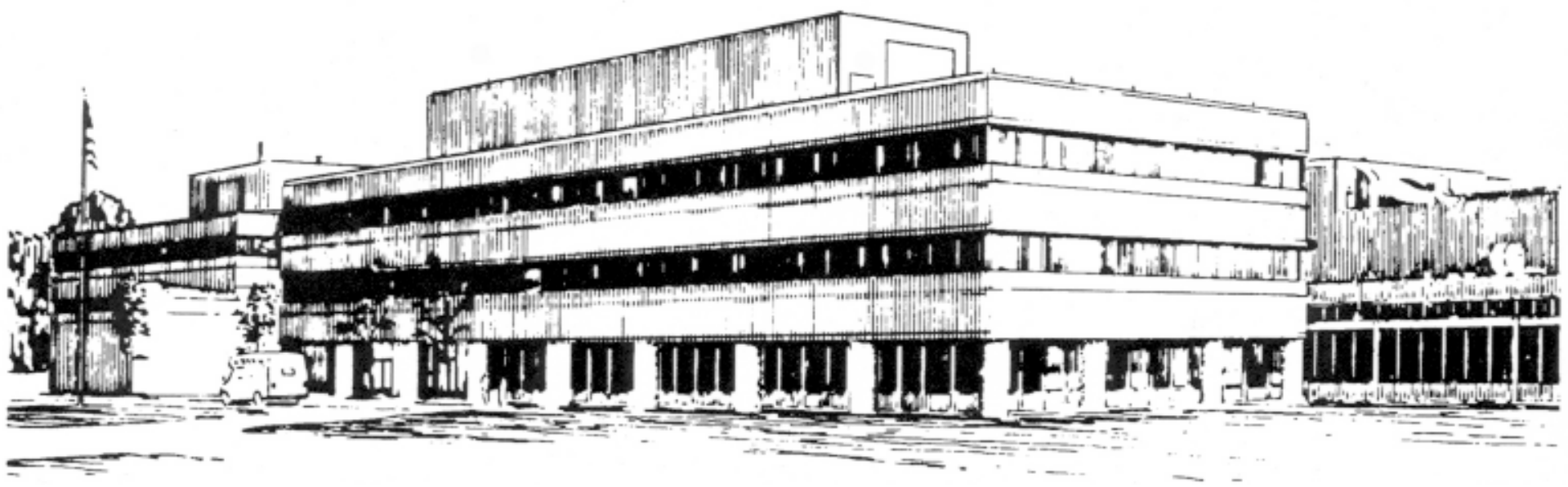

PRINCETON PLASMA PHYSICS LABORATORY PRINCETON UNIVERSITY, PRINCETON, NEW JERSEY 


\section{PPPL Reports Disclaimer}

This report was prepared as an account of work sponsored by an agency of the United States Government. Neither the United States Government nor any agency thereof, nor any of their employees, makes any warranty, express or implied, or assumes any legal liability or responsibility for the accuracy, completeness, or usefulness of any information, apparatus, product, or process disclosed, or represents that its use would not infringe privately owned rights. Reference herein to any specific commercial product, process, or service by trade name, trademark, manufacturer, or otherwise, does not necessarily constitute or imply its endorsement, recommendation, or favoring by the United States Government or any agency thereof. The views and opinions of authors expressed herein do not necessarily state or reflect those of the United States Government or any agency thereof.

\section{Availability}

This report is posted on the U.S. Department of Energy's Princeton Plasma Physics Laboratory Publications and Reports web site in FiscaL Year 2002. The home page for PPPL Reports and Publications is: http://www.pppl.gov/pub_report/

DOE and DOE Contractors can obtain copies of this report from:

U.S. Department of Energy

Office of Scientific and Technical Information

DOE Technical Information Services (DTIS)

P.O. Box 62

Oak Ridge, TN 37831

Telephone: (865) 576-8401

Fax: (865) 576-5728

Email: reports@adonis.osti.gov

This report is available to the general public from:

National Technical Information Service

U.S. Department of Commerce

5285 Port Royal Road

Springfield, VA 22161

Telephone: 1-800-553-6847 or

(703) 605-6000

Fax: (703) 321-8547

Internet: http://www.ntis.gov/ordering.htm 


\title{
Observation of Compressional Alfvén Modes during Neutral Beam Heating on the National Spherical Torus Experiment
}

\author{
E.D. Fredrickson, N. Gorelenkov, C.Z. Cheng, R. Bell, D. Darrow, D. Johnson, S. Kaye, \\ B. LeBlanc, J. Menard \\ Princeton Plasma Physics Laboratory, Princeton, New Jersey 08543 \\ S. Kubota, W. Peebles \\ Institute of Plasma and Fusion Research, Univ. of California, Los Angeles California 90095
}

\begin{abstract}
Neutral Beam Driven Compressional Alfvén Eigenmodes (CAE) at frequencies below the ion cyclotron frequency have been observed and identified for the first time in the National Spherical Torus Experiment. The modes are observed as a broad spectrum of nearly equally spaced peaks in the frequency range from $\approx 0.2$ to $\approx 1.2 \omega_{\text {ci }}$. The frequency has a scaling with toroidal field and plasma density consistent with Alfvén waves. The modes have been observed with high bandwidth magnetic pick-up coils and with a reflectometer.
\end{abstract}

Interactions of fast ion tails with magnetohydrodynamic (MHD) instabilities has long been of interest in the Magnetic Fusion Energy (MFE) community. Wave particle interactions can be harmful in that they can induce loss of energetic ions $[1,2]$ or beneficial in that they "channel" energy from the fast ion population to the thermal ion population [3] (rather than the thermal electrons). Many present experiments rely on fast ions created by radio frequency waves or from neutral beam injection (NBI) to heat the plasma. Proposed MFE fusion reactors will rely on energetic fusion alpha particles to keep the plasma at temperatures high enough to maintain thermonuclear fusion. Understanding the role played by fast ion-wave interactions in these experiments is crucial to improving the prospects for a fusion reactor.
The National Spherical Torus Experiment (NSTX) is a low aspect ratio $\left(\mathrm{R}_{\text {major }} / \mathrm{r}_{\text {minor }} \approx\right.$ $0.85 \mathrm{~m} / 0.65 \mathrm{~m}$ ) toroidal device[4]. The range of operational parameters used for the experiments discussed here are 0.7 to $1.0 \mathrm{MA}$ of toroidal plasma current, 3.0 to $4.5 \mathrm{kG}$ toroidal field, central electron density of 1- 5 $10^{19} / \mathrm{m}^{3}$, central electron temperature of up to $\approx 1 \mathrm{keV}$. The plasmas were heated with 1.5 to $3 \mathrm{MW}$ of deuterium neutral beam injection (NBI) power at a full energy of $80 \mathrm{kV}$.

The neutral beam injection energy translates to a beam ion velocity 2-4 times the Alfvén speed and thus Alfvénic waves are likely to be excited. The beam velocity is $\mathrm{V}_{\mathrm{b}} \approx$ $2.8 \times 10^{6} \mathrm{~m} / \mathrm{s}$. The Alfvén velocity is $\mathrm{V}_{\mathrm{A}} \approx 0.9$ x $10^{6} \mathrm{~m} / \mathrm{s}$ at an electron density of $3 \times 10^{19} / \mathrm{m}^{3}$ and magnetic field of $3 \mathrm{kG}$ (for a nominal 
deuterium plasma). This ratio is similar to the ratio of the velocity of fusion $\alpha$ 's to $V_{A}$ in an ST reactor. There is a large population of fast ions available to drive the wave; the calculated volume averaged beam beta is of order $20 \%$ of the total plasma beta. The NBI geometry and relatively large orbit size of the beam ions result in an anisotropic pitch angle distribution for the fast ions. This anisotropy can provide the energy source to drive instabilities. Similar anisotropies are invoked to drive waves in the earth's magnetosphere[5,6]. The instabilities driven are those where the fast ions transfer more energy to the wave than is lost through damping terms (e.g., electron and ion Landau damping on the thermal population).

The sheared magnetic field geometry, resulting from a peaked toroidal plasma current density profile together with the nonuniform magnetic field on a flux surface from toroidal geometry and elongation couple Alfvén waves of different poloidal mode numbers. This opens a continuum gap and weakly damped discrete Toroidal Alfvén Eigenmodes (TAE) inside the frequency gap $[7,8]$. Alternatively, it was shown that in cylindrical geometry, the spatial variation of the Alfvén velocity can provide the effect of a "potential well" for compressional Alfvén

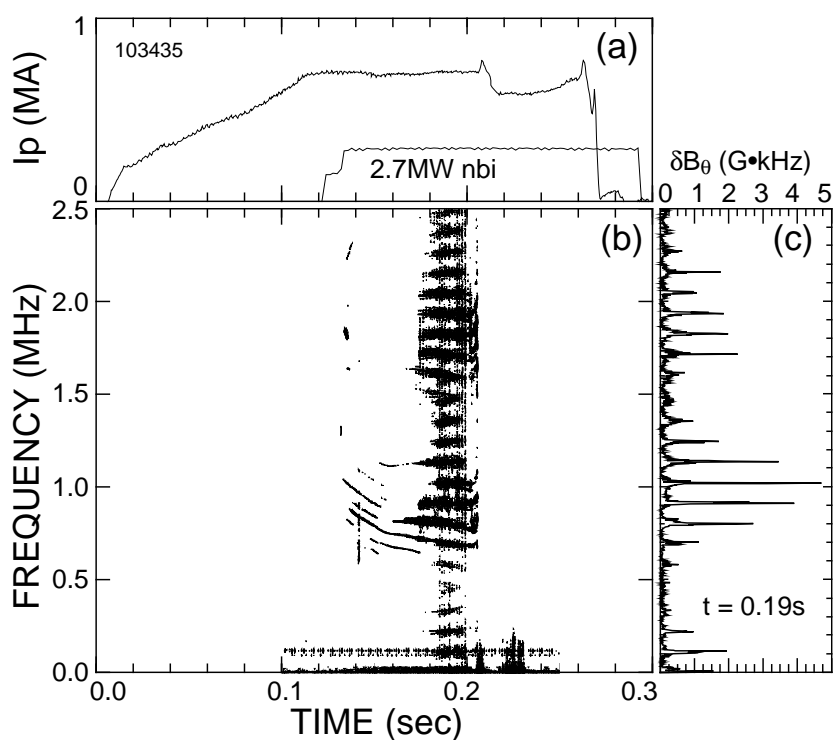

FIG. 1 a) Traces show evolution of the plasma current and neutral beam heating, b) Spectrogram of magnetic fluctuations.

waves (CAE) [9]. This cylindrical model has since been extended to toroidal geometry [10] and then low aspect ratio geometry [11]. For the CAE the effective $\mathrm{k}_{\|}$remains small and the electron and ion landau damping is weak and the drive from fast ions can destabilize the mode. A similar model has previously been invoked to explain the observation of ion cyclotron emission (ICE) from tokamak plasmas [12].

With the first injection of neutral beams on NSTX, a broad and complicated spectrum of coherent modes was seen between $\approx 400 \mathrm{kHz}$ and up to $2.5 \mathrm{MHz}$ (where $\omega_{\mathrm{ci}}$ for deuterium is $\approx 2.2 \mathrm{MHz}$ ) and less often modes in the 50 to $150 \mathrm{kHz}$ range (Fig. 1). The higher frequency modes have been identified as magnetosonic waves or compressional Alfvén eigenmodes (CAE) excited by a cyclotron resonance with 
the neutral beam ions. The lower frequency modes are thought to be related to the TAE modes seen commonly in tokamaks with energetic fast ion populations resulting from ICRF and NBI heating. There is no clear indications of enhanced fast ion losses associated with the modes.

The principal diagnostics for detecting the mode are the fast Mirnov coil array and the UCLA reflectometer [13]. The Mirnov coil design has an intrinsic bandwidth of $>3 \mathrm{MHz}$. The coils are mounted on the vacuum vessel walls, approximately $20 \mathrm{~cm}$ outside the plasma. At present there is only a limited amount of experimental data available for studying the poloidal and toroidal structure of the modes.

The data shown in Figure 1 illustrates several common features of these modes. The modes onset around 10 - $50 \mathrm{~ms}$ after the start of neutral beam injection. The mode frequencies drop with time and, in this example, the mode activity is terminated by the onset of a lower frequency MHD instability which results in a major reconnection of the magnetic flux. In Fig. 1 it is seen that the mode frequencies are approximately evenly spaced up to at least 2.5 $\mathrm{MHz}$ (the bandwidth of the system). The mode spacing in this example is nearly uniform at about $130 \mathrm{kHz}$ and the peaks appear in two bands spanning $400-1500 \mathrm{kHz}$ and $1500-2500 \mathrm{kHz}$. The bands are not only apparent in amplitude, but also subtle variations in the spacing of the frequency

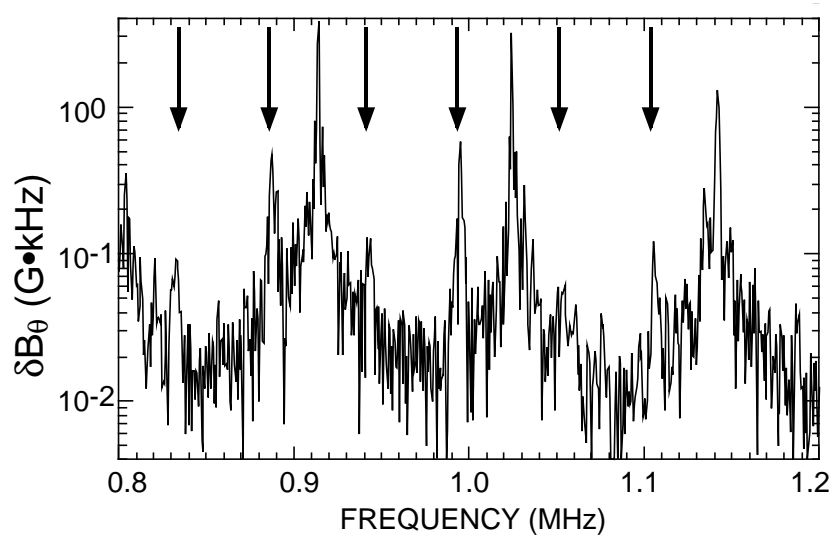

FIG. 2. Higher resolution spectrum of the data shown in Fig. 1 at 0.197s showing finer splitting of the peaks. peaks suggest that these are distinct bands, e.g., the frequency gap at $1.53 \mathrm{MHz}$ is slightly wider, even though the spacing of the gaps in each of the bands is very similar. In Fig. 2 is shown a higher resolution spectrum of the same data from slightly later in time. Each of the peaks now has satellite peaks shifted by $\approx$ $25 \mathrm{kHz}$. Detailed measurements of the mode localization have not yet been done. However the initial data from the reflectometer shows that the mode does drive density fluctuations in the plasma (Fig. 3). The reflectometer measures the displacement of constant density contours. While there is qualitative similarity in the spectra, there is not a direct correlation of spectral peaks between the magnetic fluctuation data and the reflectometer data, possibly as a result of the internal vs. edge locations of the measurements, the different parameters being measured or the fast timedependence of the spectrum. 


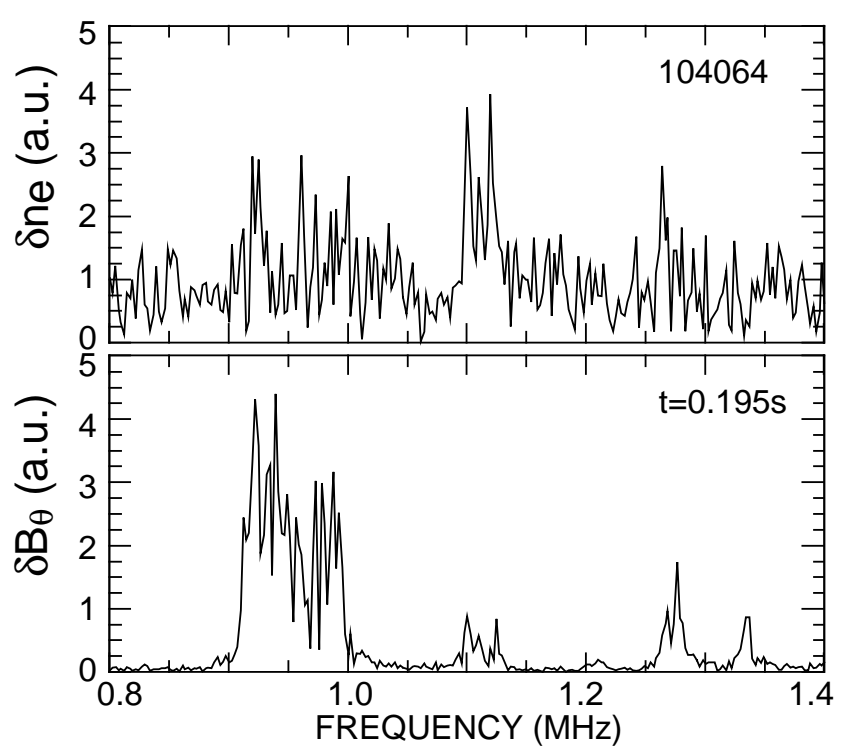

FIG. 3. Spectra of density fluctuations as measured with the reflectometer and compared to magnetic fluctuation spectra at the same time.

Scaling of the mode frequency with toroidal field and density was studied by ramping the toroidal field up and down in similar shots and by the natural density evolution in each plasma discharge. In Fig. 4 are shown spectra from two similar plasmas, the first in which the toroidal field was ramped upward, the second in which the toroidal field was ramped downward (in both cases the ramps began at $0.13 \mathrm{~s}$ ). The evolution in the density was similar for these two shots. The dependence of the mode frequency on magnetic field is found by tracking a large mode in each plasma, starting at the same

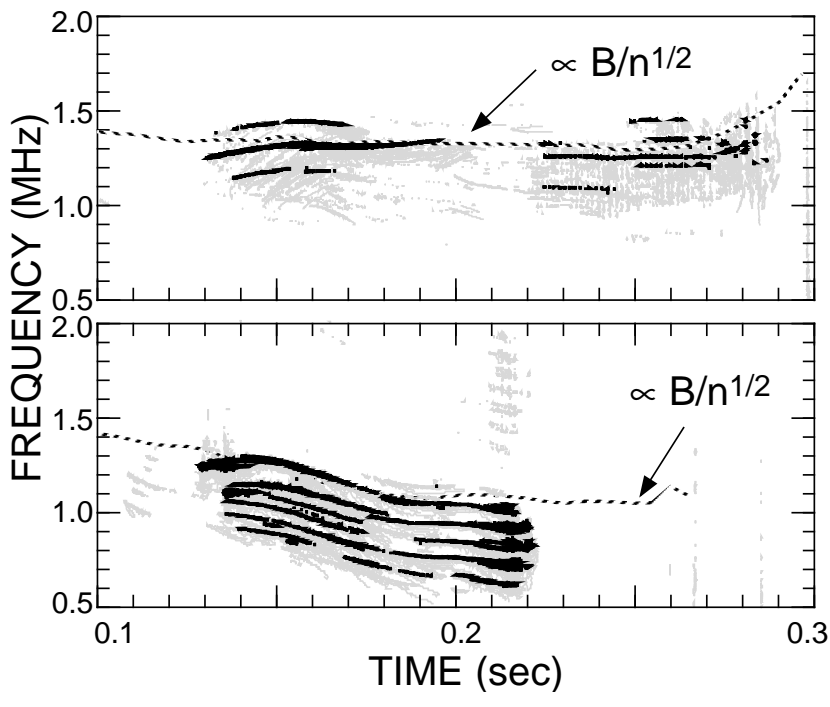

FIG. 4. Magnetic fluctuation spectra from two nearly similar shots, a) with a upward ramp in toroidal field, b) with a downward ramp (shot \# 103932,103936).

frequency $(\approx 1.3 \mathrm{MHz})$ prior to the field ramp. The magnetic field evolution is calculated in TRANSP, and the time dependence of $\bmod (\mathrm{B}) / \mathrm{n}^{1 / 2}$ at a major radius of $1 \mathrm{~m}$ is over laid as the dashed line. The difference in $\bmod (\mathrm{B})$ between the two shots at $0.2 \mathrm{~s}$ was about $27 \%$ and the difference in mode frequency is about $25 \%$. In these early NSTX plasmas, the density increases nearly linearly during the neutral beam injection period and it is not possible to perform similar comparison experiments as was done for the toroidal field scan. The downward evolution of frequency during NBI is, however, roughly consistent with the square root density dependence. From these experiments it was found that the mode frequency showed Alfvénic dependence, being proportional to the magnetic field strength and inversely as roughly the square root of the density. 
The mode behavior varies between quasisaturated modes with nearly constant amplitude to a bursting behavior reminiscent of the fishbone instability [1]. All of the modes have the same time behavior. The period between bursts is $\approx 2 \mathrm{~ms}$ and the duration of a burst is $\approx 0.1-0.2 \mathrm{~ms}$. In Fig. 5 is shown the magnetic fluctuation signal on a short time scale. During the bursts, the growth rate for the envelope of modes is approximately $10^{4} / \mathrm{s}$, or $0.1 \%$ of the mode frequency and the damping rate is comparable or slightly faster.

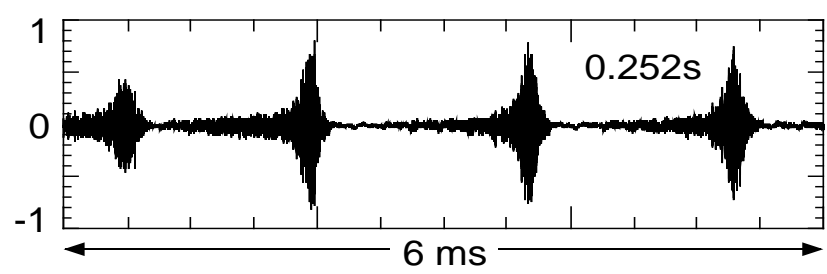

FIG. 5. Mirnov coil signals over a short time interval showing the bursting character of the modes.

The stability of modes is determined by the fast ion population, but the mode frequency appears to be a property of the background plasma, i.e., the modes are not fast ion or energetic particle modes. In Fig. 6 is shown a spectrogram of magnetic fluctuations where the NBI injection angle, thus fast ion pitch angle, has been changed at $0.22 \mathrm{~s}$. As can be seen, some modes persist through the change, indicating that

the mode frequency is a background plasma parameter. Other modes are stabilized, indicating that the new fast ion distribution does not couple to them.
The modes have been identified as compressional Alfvén eigenmodes. In previous work [9-11] it was shown that the radial CAE structure is approximately described by a harmonic oscillator equation where the effective potential is described by $\mathrm{V}(\mathrm{r})=\mathrm{m}^{2} / \mathrm{r}^{2}-\omega^{2} / \mathrm{V}_{\mathrm{A}}^{2}$ where $\mathrm{m}$ is the poloidal mode number. In toroidal geometry, this potential can form a well in both the radial

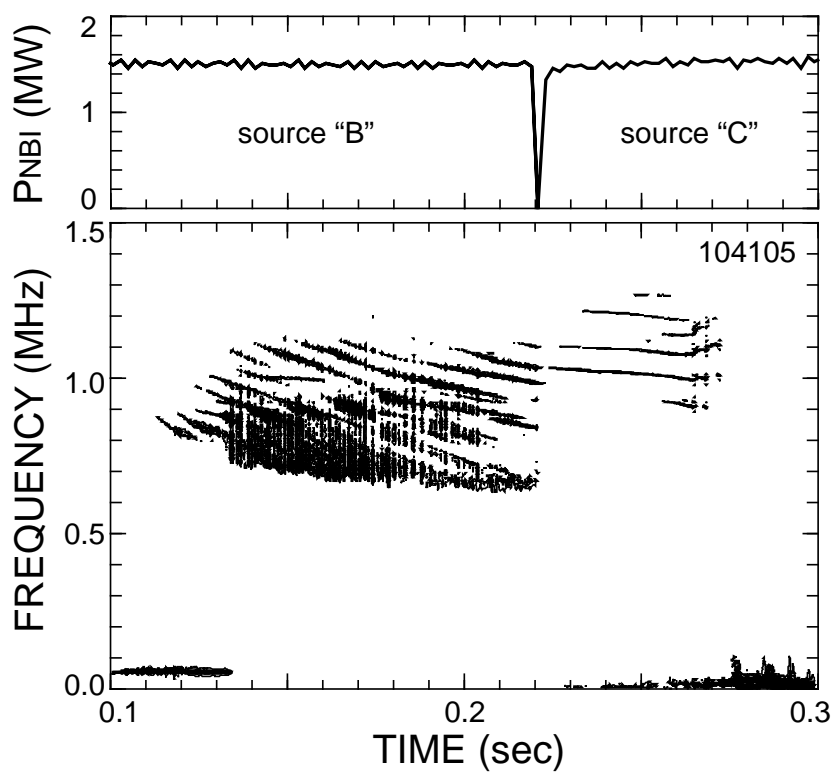

FIG. 6. Spectrogram of magnetic fluctuations through a switch from a shallower NBI to a deeper NBI source. and poloidal directions depending on the shape of the density profile and the variation of the magnetic field intensity in the poloidal direction. If the potential forms a well, the solutions yield the eigenfrequency spectrum described by $\omega^{2}=\mathrm{m}^{2} \mathrm{~V}_{\mathrm{A}}{ }^{2} / \kappa^{2} \mathrm{r}^{2}\left(1+\mathrm{k}_{\|}{ }^{2} \kappa^{2} \mathrm{r}^{2} / \mathrm{m}^{2}\right)$ $\left[1+\left(1+1 / \sigma_{i}\right)(2 s+1) \Delta^{2} / r^{2}\right]$. The mode is localized to the potential well in both the radial and poloidal directions. In this expression $\mathrm{s}$ represents the radial wave number. The 
parameters $\kappa$ and $\sigma_{\mathrm{i}}$ are geometric constants of order unity related to the radial and poloidal structure of the potential well. The parameter $\Delta$ is a measure of the mode radial localization. The closed geometry in the toroidal direction also results in discrete values for the parallel wave number, $\mathrm{k}_{\|}=(\mathrm{m}-\mathrm{nq}) / \mathrm{qR}$. The toroidal wave number $\mathrm{n}$ provides the fine-scale splitting in the spectrum.

The mode drive comes from the perpendicular energy of super-Alfvénic NBI particles via particle - wave Doppler shifted cyclotron resonance [11]. The resonance is described by $\omega-\mathrm{k}_{\|} \mathrm{V}_{\| \mathrm{b}}-\mathrm{k}_{\theta} \mathrm{V}_{\mathrm{dr}}-\mathrm{I} \omega_{\mathrm{cD}}=0$ for $\mathrm{I}$ $=1$. The velocity space anisotropy of the beam ions creates a "bump-on-tail"-like distribution in the $\mathrm{v}_{\perp}$ direction. The positive velocity gradient drives the CAE instability.

Simulations of the mode spectrum in simplified geometry have been done. The multiple "bunches" of peaks in the spectrum have been reproduced, however only qualitative agreement with the observed mode spectrum has been found. A representative spectrum is shown in Fig. 8 where the parameter $\kappa$ was adjusted to give the observed spacing of the bunches. A more complete simulation of the mode behavior is being pursued.

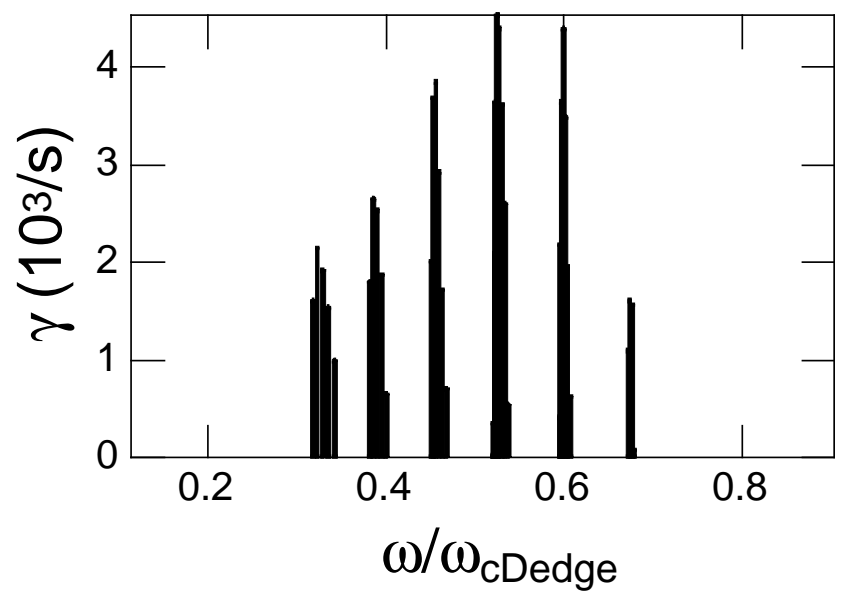

FIG. 8. Simulation of CAE modes showing the predicted multiple spectral peaks possible with this model.

In summary, multiple, coherent modes at frequencies up to the deuterium ion cyclotron frequency were observed during neutral beam injection heating of the National Spherical Torus Experiment (NSTX). The modes were seen predominantly in the frequency range of $0.4 \mathrm{kHz}$ to $2.5 \mathrm{MHz}$. The modes are Alfvénic in character in that the mode frequency scales nearly linearly with magnetic field and inversely with the square root of the density. They have been identified as compressional Alfvén waves excited by a resonant interaction with the energetic beam ions. The modes are predicted to be localized near the plasma edge. The parametric scaling of the mode frequency with density and magnetic field is consistent with CAE modes. To date there has been no observation of enhanced beam ion loss associated with the mode activity. Rather the presence of the modes may enhance the transfer of energy from the fast ions to the thermal electrons or ions[14]. 
The authors greatly appreciate the support of the NSTX group, particularly Dr. D. Gates, in these experiments. This work supported by U.S. DOE Contract DE-AC02-75CH03073 and Grant Nos. DE-FG03-99ER54527 and DE-FG03-86ER53225.

[1] L. Chen, R. B. White, M.N. Rosenbluth, Phys. Rev. Lett. 52 (1984) 1122.

[2] R.B. White, E.Fredrickson, D. Darrow, M. Zarnstorff, R. Wilson, S. Zweben, K. Hill, Y. Chen, and G. Fu, Phys. Plasmas 2 (1995) 2871.

[3] N.J. Fisch, J-R. Rax, Phys. Rev. Lett. 69 (1992) 612.

[4] M. Ono, et al., Nucl. Fusion 40 (2000) 557.

[5] S. M. Kaye, M.G. Kivelson, and D.J. Southwood, Journal of Geo. Phys. Res. 84, (1979) 6397.

[6] C.Z. Cheng and Q. Qian, J. of Geophysical Res. 99, (1994) 11193.
[7] C.Z. Cheng and M.S. Chance, Phys. Fluids 29, (1986) 2471.

[8] K.L. Wong, R.J. Fonk, S.F. Paul, et al., Phys. Rev. Lett. 66, (1991) 1874.

[9] S.M. Mahajan , D.W. Ross, Phys. Fluids 26 (1983) 2561.

[10] B. Coppi, S. Cowley, R. Kulsrud, P. Detragiache, and F. Pegoraro, Phys. Fluids 29, (1986) 4060.

[11] N.N. Gorelenkov, C.Z. Cheng, Nucl. Fusion 35, (1995) 1743.

[12] S. Cauffman and R. Majeski, Rev. Sci. Instrum. 66, (1995) 817.

[13] S. Kubota, X.V. Nguyen, W.A. Peebles, et al., Rev. Sci. Instrum., 72, (2001) 348.

[14] D. Gates, R. White, N. Gorelenkov, (submitted to Phys. Rev. Lett. May 2001). 


\section{External Distribution}

Plasma Research Laboratory, Australian National University, Australia

Professor I.R. J ones, Flinders University, Australia

Professor J oão Canalle, Instituto de Fisica DEQ/IF - UERJ , Brazil

Mr. Gerson O. Ludwig, Instituto Nacional de Pesquisas, Brazil

Dr. P.H. Sakanaka, Instituto Fisica, Brazil

The Librarian, Culham Laboratory, England

Library, R61, Rutherford Appleton Laboratory, England

Mrs. S.A. Hutchinson, JET Library, England

Professor M.N. Bussac, Ecole Polytechnique, France

Librarian, Max-Planck-Institut für Plasmaphysik, Germany

J olan Moldvai, Reports Library, MTA KFKI-ATKI, Hungary

Dr. P. Kaw, Institute for Plasma Research, India

Ms. P.J . Pathak, Librarian, Insitute for Plasma Research, India

Ms. Clelia De Palo, Associazione EURATOM-ENEA, I taly

Dr. G. Grosso, Instituto di Fisica del Plasma, Italy

Librarian, Naka Fusion Research Establishment, J AERI, J apan

Library, Plasma Physics Laboratory, Kyoto University, J apan

Research Information Center, National Institute for Fusion Science, J apan

Dr. O. Mitarai, Kyushu Tokai University, J apan

Library, Academia Sinica, Institute of Plasma Physics, People's Republic of China

Shih-Tung Tsai, Institute of Physics, Chinese Academy of Sciences, People's Republic of China

Dr. S. Mirnov, TRINITI, Troitsk, Russian Federation, Russia

Dr. V.S. Strelkov, Kurchatov Institute, Russian Federation, Russia

Professor Peter Lukac, Katedra Fyziky Plazmy MFF UK, Mlynska dolina F-2, Komenskeho Univerzita, SK-842 15 Bratislava, Slovakia

Dr. G.S. Lee, Korea Basic Science Institute, South Korea

Mr. Dennis Bruggink, Fusion Library, University of Wisconsin, USA

Institute for Plasma Research, University of Maryland, USA

Librarian, Fusion Energy Division, Oak Ridge National Laboratory, USA

Librarian, Institute of Fusion Studies, University of Texas, USA

Librarian, Magnetic Fusion Program, Lawrence Livermore National Laboratory, USA

Library, General Atomics, USA

Plasma Physics Group, Fusion Energy Research Program, University of California at San Diego, USA

Plasma Physics Library, Columbia University, USA

Alkesh Punjabi, Center for Fusion Research and Training, Hampton University, USA

Dr. W.M. Stacey, Fusion Research Center, Georgia Institute of Technology, USA

Dr. J ohn Willis, U.S. Department of Energy, Office of Fusion Energy Sciences, USA

Mr. Paul H. Wright, Indianapolis, Indiana, USA 
The Princeton Plasma Physics Laboratory is operated by Princeton University under contract with the U.S. Department of Energy.

\author{
Information Services \\ Princeton Plasma Physics Laboratory \\ P.O. Box 451 \\ Princeton, NJ 08543
}

Phone: 609-243-2750

Fax: 609-243-2751

e-mail: pppl_info@pppl.gov

Internet Address: http://www.pppl.gov 